\title{
Urgences
}

\section{Correspondance (dessin de Jacqueline Chénard)}

\section{Richard Corriveau}

Numéro 6, 4e trimestre 1982

URI : https://id.erudit.org/iderudit/025087ar

DOI : https://doi.org/10.7202/025087ar

Aller au sommaire du numéro

Éditeur(s)

Urgences

ISSN

0226-9554 (imprimé)

1927-3924 (numérique)

Découvrir la revue

Citer ce document

Corriveau, R. (1982). Correspondance (dessin de Jacqueline Chénard). Urgences, (6), 7-13. https://doi.org/10.7202/025087ar d'utilisation que vous pouvez consulter en ligne.

https://apropos.erudit.org/fr/usagers/politique-dutilisation/ 


\section{RICHARD CORRIVEAU}

\section{Correspondance}

(dessin de Jacqueline Chénard) 


\section{SALUT ITOU}

Salut itou à tout tata quilirata ou délirata

Sa lut vi eux frè re (qui sau te comme ma machine)

que je devrais peut-être nommer jeune

pour prendre le contrepoint et faire le pied

mais j'ai toujours préféré le contraire

de jour comme de nuit

à présent cela n'y change rien

pas grand couche en tout cas

toi (ausssssti) aussi parfois avec tes accents d'addolorata passion-

/née

tu ressembles à un bateleur sans voix

qui regarde avec l'assurance de la bête menaçante

les autres ce qu'ils en pensent et s'en fout finalement

tu ressembles à un batelier sans rame n'importe où

sauf sur le Styx là sont plongées les ombres de ceux qui se sont

/livrés

à la colère ou à la paresse

tu ressembles à un passeur de dope

qui voudrait bien ne pas fumer si au moins

les pastilles pour la gorge ne lui donnaient pas mal aux dents 
tu ressembles au bateleur au batelier au passeur au passé mais le passé c'est pour les têtes

pas pour les queues de brouillard et les poches coincées dans le jeu l'angoisse n'étant plus qu'une vieille habitude existentielle que le hasard délaisse de plus en plus ou au mieux ne couche plus que sur papier le passé vit toujours quelque part dans une circonvolution crânienne muséologique du regret et remonte parfois jusqu'aux zones sous-cutanées polyglottes pour voir le jour où il en est en attendant la nuit pour rêver il n'y a pas à dire tu t'es donné le beau rôle combine par la 79 la 80 pis la 81 dans leurs coins!

aller se baigner dans l'eau et se réveiller dans le rêve jusqu'au cou...

et puis peut-être bien que les phalènes du silence détruiront tout et puis après, hein?!

il y aura toujours à redire sur le sérieux du nombre et les bigoudis de la voisine Silforine qui s'engroseille à chaque printemps d'un herbier giboyeux final qui $n^{\prime}$ en finit pas

LA MUSARAIGNE!

LE big bang!

L'HOLOCAUSTE!

LA BOMBE A MOIGNONS!

tout ça n'y changera rien

les coeurs continueront de saigner

et les théoriciens nous feront bâiller d'aise

et moi aussi

la mouche qui craque entre deux vitres et deux saisons

je m'en ferai de ce qui ne m'arrive pas

I'm sorry nous sommes seuls

m'apparaissant dès lors une volupté antithétique dont je me passerai de gré ou de force quelle importance

dans la Beauce ce n'est pas les embâcles qui nous font peur c'est l'eau qui noie et charrie tout quand il y a de la glace à casser c'est que nous sommes deux voilà tout 


\section{et moi aussi}

la monche qui crajue

einti vein vitres

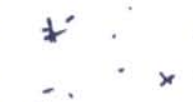

$1 * i$

$\therefore \quad 1 * 1$

. S İVA

$\therefore \quad \because a^{*}$

et $2 \ddot{2}$ saisons

$$
\begin{aligned}
& \text {...... } \\
& \because \vdots \vdots \vdots \vdots \vdots 0)
\end{aligned}
$$

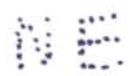

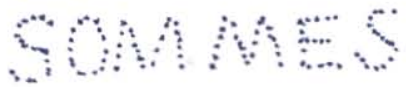

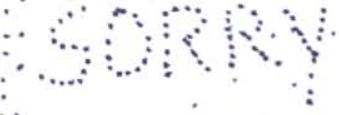

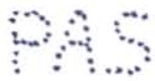
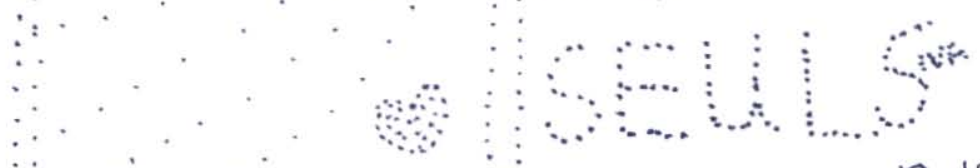
tous les discours devraient perdre un peu de cette ride qui les achemine lentement non pas vers la sagesse comme on voudrait bien nous le faire croire mais plutôt vers la mort LES DISCOURS SONT DES TERRORISTES QUI TUENT AU HASARD DES JUSTIFICATIONS

il faudrait que nous arrivions à les délier avec le couteau à deux lames de l'humour mais sans oublier surtout de faire disparaître l'arme du crime "Ne m'arrêtez pas, je suis léger, je suis léger, je suis si léger que vos visages me font peur tant je les vois ces rides qui me sourient." pendant que la parole se grenouille je suis assez boeuf de l'ouest pour brailler sur ma bouse 


\section{SALUT MUTANT}

salu't mutant du dernier monde numismatique

à la peau rosbif de celui qui écoute repartir le train

et qui se demande ce que pouvait bien contenir l'éprouvette

que les alchimistes de la face lui ont fait ingurgiter

d'un seul trait d'un seul coup cul sec hara-kiri

sans regarder de peur du sang

qui macule la lame de l'univers barbare sophistiqué vieilli ou inouï mais chromé donc raté ratatiné parce que trop or

et oublié au plus fort de la tempête

dans le verre du naufragé

obsédé de ce qui n'est pas encore

juste avant la plage planche sur le dos au soleil

et hanté de ce qui n'est plus vraiment

juste après dans le sable de nos phantasmes mièvres

quand on s'en retourne pleurer homard sans pince

chacun dans notre mer morte asséchée assoiffés

clochards de la salive que nous sommes et qui nous manque

dans les moments de haute attente virgule bégaiement 
tu t'imagines dans la rue de la littérature une morue hors de son bocal qui se paie du bon temps ou du moins bon un journal d'une langue inconnue et une bonne bouteille d'ailleurs oléoliti

les actes crient eux aussi plus sûrs encore que la rime les discours déculpabilisants le sage s'en passe

"no one is free until we are all free" (Julian Beck)

"personne n'est libre tant que nous ne sommes pas tous libres"

et le plaisir clandestin cessera alors de faire mal et toutes les cages disparaîtront en même temps que les sages qui se seront ouverts tout à coup révolvant l'énigme par hasard eurêka

tu t'imagines alors dans la rue de la littérature toutes les morues séchées qui auront soif de liberté 